\title{
Dipslide cultures in the investigation of suprapubic urinary bladder aspirates of infants and children
}

\author{
ANJA AI KOSTIALA AND J PYLKKÄNEN \\ From the Department of Bacteriology and Immunology, and the Children's Hospital, University of Helsinki, \\ Helsinki, Finland
}

SUMMARY Suprapubic aspirates (SPAs) of the urinary bladder obtained from 793 infants and children with suspected urinary tract infection were grown on dipslides inoculated at the bedside as well as being cultured aerobically and anaerobically. In general, the findings on dipslides were in good agreement with those in the other culture media. The majority of the 403 dipslide-positive samples contained $10^{5}$ or more bacteria $/ \mathrm{ml}$; only in $2 \%$ was bacterial density less than $10^{3} / \mathrm{ml}$. There were five specimens with no growth on dipslides; however, an organism considered to be significant for the patient was isolated in the other cultures. Thus dipslides proved to be adequate for the culture of most SPAs, but samples from patients with urological problems should be studied by more complete methods.

Significant bacteriuria is generally held to occur when there are at least $10^{5} \mathrm{bacteria} / \mathrm{ml}$ of clean-voided urine, and findings of $10^{3} / \mathrm{ml}$ or less are considered to be insignificant. However, any amount of bacteria, excluding common skin contaminants, in a suprapubic aspirate (SPA) of the urinary bladder is thought to be significant. ${ }^{1}$ In certain cases, only suprapubic aspiration of urine seems to offer a correct diagnosis of urinary tract infection, especially in infants and children, and complications are rare. ${ }^{2-4}$

Dipslide cultures have been found useful for the diagnosis and follow-up of urinary tract infections from clean-voided urine specimens. ${ }^{35-8}$ However, low bacterial counts have not always been reliably detected on dipslides, which of course, is insignificant for clean-voided urine. ${ }^{6}$ Therefore, we decided to investigate the occurrence of low bacterial counts in SPAs of infants and children, and to compare findings on dipslides and plates inoculated at the bedside with those of aerobic and anaerobic cultures from SPA samples taken to the laboratory in a transport medium.

\section{Material and methods}

\section{PATIENTS}

In the first part of the study, 469 infants and children, aged from 1 day to 15 years, were studied in the Children's Hospital for suspected urinary tract infection by suprapubic aspiration of the bladder. The second part included 324 consecutive SPAs obtained with the same indication.

SUPRAPUBIC ASPIRATION

Whenever possible, the percutaneous suprapubic aspiration of the urinary bladder was performed when at least 2 hours had elapsed from previous urination. The technique of Saccharow and Pryles ${ }^{9}$ was used. No complication other than occasional microscopic haematuria was seen.

TRANSPORTATION AND CULTURE OF URINE In the first part of the study, the SPA was seeded at the bedside on to two different media using the aspiration syringe equipped with a fresh needle. A dipslide coated on one side with CLED medium and on the other with MacConkey agar (Uricult ${ }^{\mathbf{R}}$, Orion Diagnostica, Helsinki, Finland) as well as a blood agar plate (Orion Diagnostica) were used. In the second part of the study, a chocolate agar plate (Orion Diagnostica) was substituted for blood agar, and a part of the SPA was also placed under the agar of a transport tube (Transpocult ${ }^{\mathrm{R}}$, Orion Diagnostica). The dipslide and blood agar were incubated in air and the chocolate agar in $\mathrm{CO}_{2}$ for 18 hours at $37^{\circ} \mathrm{C}$. Aliquots of approximately $0.1 \mathrm{ml}$ urine from the transport tube were seeded on to blood agar, chocolate agar, and CLED medium (Oxoid, Hants, UK) plates. A menadione-cysteine blood agar plate and kanamycin-vancomycin chocolate 
agar plate ${ }^{10}$ were also inoculated and incubated anaerobically (GasPak ${ }^{R}$ Anaerobic Systems, BBL, Cockeysville, Md, USA) for 48 hours at $37^{\circ} \mathrm{C}$. If growth occurred the species were identified by standard bacteriological methods. ${ }^{1}$ The amount of growth on dipslides was classified according to factory specifications from $<10^{3}$ to $10^{7} / \mathrm{ml}$. An attempt was made to quantitate the findings on plates inoculated at the bedside by counting the colonies per plate to allow classification as light (less than 10 colonies), moderate, or heavy growth (uniform carpet of colonies).

\section{Results}

Dipslides and blood agar plates inoculated at the bedside are compared in Table 1 . It can be seen that there were three dipslide-negative SPAs; however, blood agar plates showed light growth. Escherichia coli was identified in all cases. It was considered to be a significant finding for one patient, whereas the two others received no medication, and a cleanvoided urine control specimen gave no growth. Correspondingly, E. coli grew three times at $10^{4}$ or $10^{5} / \mathrm{ml}$ on dipslides, but the plates were negative. However, since control specimens were sterile, all these isolates were judged to be without clinical importance. The majority $(217 / 261)$ of dipslidepositive cultures from SPA had high numbers of bacteria $\left(\geq 10^{5} / \mathrm{ml}\right)$. Low counts $\left(<10^{3} / \mathrm{ml}\right)$ were seen in only two cases.

In the second part of the study, the need for more complete bacteriological isolation methods was studied. The results in Table 2 demonstrate five positive cases from the transport tube among 177 SPAs with no growth on dipslides or chocolate agar plates inoculated at the bedside. The isolates were Staphylococcus aureus, Staph. epidermidis, enterococcus, Acinetobacter sp. and Enterobacter sp. as well as Bacteroides fragilis. Since clean-voided control specimens were negative, the first four cases were thought to be skin contaminants without clinical significance. B. fragilis was isolated from the SPA of a patient with an anus vestibularis during sulphonamide medication.

In five instances, dipslides were negative, but light growth was seen on bedside plates. Three yielded the same bacterium found in cultures from transport medium. Of these, two patients with $E$. coli were treated, whereas one sample growing enterococci was negative when controlled and was considered to be clinically unimportant. One of the two that were negative in tube cultures was thought to be a contaminant on the plate (enterococcus); the other grew $\alpha$-haemolytic streptococci and Haemophilus influenzae (not type b). This patient was treated. In addition, the SPAs of three patients with $E$. coli ( $>10^{5} / \mathrm{ml}$ on dipslides and a heavy growth on bedside plates) also yielded enterococci, except $E$. coli, in transport medium cultures (not seen in Table 2). Enterococci were considered to be contaminants.

Dipslide was the only medium showing growth in four specimens. In three instances, the isolate was $E$. coli $\left(<10^{3} / \mathrm{ml}, 10^{3} / \mathrm{ml}\right.$, and $\left.10^{6} / \mathrm{ml}\right)$, and, in one, $\alpha$-haemolytic streptococcus $\left(10^{4} / \mathrm{ml}\right)$. Clean-

Table 1 Comparison of dipslide colony counts and growth on blood agar plates in 469 suprapubic urinary bladder aspirates

\begin{tabular}{ccccc}
\hline Dipslide colony count/ml & \multicolumn{2}{l}{ Number of blood agar plates with: } & \\
\cline { 2 - 5 } & No growth & Light growth & Moderate growth \\
\hline 0 & 205 & 3 & 0 & Heavy growth \\
$<10^{3}$ & 0 & 2 & 0 & 0 \\
$10^{3}$ & 0 & 13 & 3 & 0 \\
$10^{4}$ & 2 & 1 & 6 & 2 \\
$\geq 10^{5}$ & 1 & 2 & 8 & 206 \\
\hline
\end{tabular}

Table 2 Comparison of dipslide colony counts, growth on chocolate agar plates, and growth from a transport medium in 324 suprapubic urinary bladder aspirates

\begin{tabular}{|c|c|c|c|c|}
\hline \multirow[t]{2}{*}{ Dipslide colony count/ml } & \multicolumn{4}{|c|}{ Number of chocolate agar plates with: } \\
\hline & No growth & Light growth & Moderate growth & Heavy growth \\
\hline $\begin{array}{r}0 \\
<10^{3} \\
10^{3} \\
10^{6} \\
\geq 10^{5}\end{array}$ & $\begin{array}{c}177(5)^{*} \\
1(0) \\
1(0) \\
1(0) \\
1(0)\end{array}$ & $\begin{array}{l}5(3) \\
1(1) \\
4(4) \\
0(0) \\
0(0)\end{array}$ & $\begin{array}{l}0(0) \\
3(3) \\
6(6) \\
7(7) \\
6(6)\end{array}$ & $\begin{array}{c}0(0) \\
0(0) \\
2(2) \\
6(6) \\
103(103)\end{array}$ \\
\hline
\end{tabular}

*The figures in parentheses denote the number of positive aerobic or anaerobic cultures from the transport medium. 
voided control specimens were studied, and because they were sterile the patients were not treated. The majority $(110 / 142)$ of dipslide-positive cultures had a high $\left(\geq 10^{5} / \mathrm{ml}\right)$ bacterial count, whereas those with less than $10^{3} / \mathrm{ml}$ were seen only five times.

Taken together, the results show that $327(81 \%)$ of the 403 dipslide-positive patients had a high bacterial count. In seven cases $(2 \%)$, bacterial density was less than $10^{3} / \mathrm{ml}$. In addition, $13(3 \%)$ of the 390 dipslide-negative aspirates showed growth when cultured by more complete methods. However, only five $(1 \%)$ were thought to be clinically significant. One of these isolates was $B$. fragilis. Seven $(2 \%)$ of 403 dipslide-positive SPAs were negative in other cultures and were considered clinically insignificant. With these exceptions, the individual isolates on dipslides and in other culture media were in good agreement with each other.

\section{Discussion}

The results presented indicate that the majority of SPAs contained high numbers of bacteria $/ \mathrm{ml}$. It has been shown that there is a good correlation between dipslide and pourplate counts when the density of urinary bacteria is at least $10^{4} / \mathrm{ml}$, and that specimens containing fewer than $10^{2}$ organisms $/ \mathrm{ml}$ may give no growth on dipslides. ${ }^{5-7}$ In the present material, among 793 SPAs there were five cases that were dipslide-negative, yet clinically significant isolations (three of them $E$. coli) were done in other cultures. However, when the number of culture media is increased, the risk of obtaining contamination findings also increases. This was seen especially in transport medium cultures. The growth of bacteria during transportation is avoided by the use of dipslides inoculated immediately after bladder aspiration. They also are inhibitory to common skin contaminants, whereas richer culture media may allow their growth.

Increasing knowledge about anaerobic bacteria has prompted a search for them also in urinary tract infections. Since anaerobes are part of the normal flora of the urethra, suprapubic bladder aspiration has been recommended as the method of choice for obtaining a sample for anaerobic culture. It has been found that anaerobes may be associated with urological problems but otherwise their role in urinary tract infections seems to be rather insignificant. ${ }^{11-14}$ In accordance with this, in the present study the only anaerobic isolate was $B$. fragilis, found in the SPA of a child with a urinary tract anomaly.
Dipslides keep well and allow quantitation of urinary bacteria. They were found to be adequate for the culture of the majority of SPAs. However, negative results may be obtained in the rare cases in which bacterial density in urine is very low or the causative agent is a fastidious organism. This can be avoided by the additional use of a chocolate agar plate seeded at the bedside. SPAs from patients with urological problems should be cultured anaerobically.

This study was supported by a grant from the Sigrid Juselius Foundation, Helsinki, Finland.

\section{References}

${ }^{1}$ Lennette EH, Spaulding EH, Truant JP. Manual of Clinical Microbiology. 2nd ed. Washington DC: American Society for Microbiology, 1974.

${ }^{2}$ Pryles CV, Lustik B. Laboratory diagnosis of urinary tract infection. Pediatr Clin North Am 1971;18:233-44.

${ }^{3}$ Pylkkänen J, Vilska J, Koskimies O. Diagnostic value of symptoms and clean-voided urine specimen in childhood urinary tract infection. Acta Paediatr Scand 1979;68: 341-4.

${ }^{4}$ Medical Research Council. Responsibility in investigations on human subjects. Br Med J 1964;2:178-80.

${ }^{5}$ Cohen SN, Kass EH. A simple method for quantitative urine culture. $N$ Engl J Med 1967;277:176-80.

- Guttmann D, Naylor GRE. Dip-slide: An aid to quantitative urine culture in general practice. Br Med J 1967;3:343-5.

${ }^{7}$ Mackey JP, Sandys GH. Laboratory diagnosis of infections of the urinary tract in general practice by means of a dip-inoculum transport medium. $\mathrm{Br} \mathrm{Med} J$ 1965;2: 1286-8.

8 Parkkulainen KV, Kosunen TU. A follow-up study of bacteriuria in female patients treated for recurrent urinary tract infections using dip-slides. Ann Clin Res 1971;3:163-7.

${ }^{9}$ Saccharow L, Pryles CV. Further experience with the use of percutaneous suprapubic aspiration of the urinary bladder. Bacteriological studies in 654 infants and children. Pediatrics 1969;43:1018-24.

${ }^{10}$ Smith LDS, Holdeman LV. The Pathogenic Anaerobic Bacteria. Springfield, Illinois: Charles C Thomas, 1968.

11 Finegold SM, Martin WJ, Scott EG, eds. Microorganisms encountered in the urinary tract. In: Bailey and Scott's Diagnositc Microbiology. 5th ed. Saint Louis, Missouri: CV Mosby Company, 1978;75-9.

Headington JT, Beyerlein B. Anaerobic bacteria in routine urine culture. J Clin Pathol 1966;19:573-6.

${ }^{13}$ Martin WJ, Segura JW. Urinary tract infections due to anaerobic bacteria. In: Balows A, DeHaan RM, Dowell VR, Jr, Guze LB, eds. Anaerobic Bacteria. Role in Disease. Springfield, Illinois: Charles C Thomas, 1974;359-67.

14 Segura JW, Kelalis PP, Martin WJ, Smith LH. Anaerobic bacteria in the urinary tract. Mayo Clin Proc 1972;47: 30-3.

Requests for reprints to: Dr AAI Kostiala, Department of Bacteriology and Immunology, University of Helsinki, Haartmaninkatu 3, 00290 Helsinki 29, Finland. 